\title{
ANALYSIS ON IMPACT OF COMPACT CITY PROGRESS ON SEISMIC RISK FLUCTUATION
}

\author{
HARUMI YASHIRO \& TAKAYUKI HAYASHIN \\ Department of civil and environment engineering, National Defense Academy, Japan
}

\begin{abstract}
It is estimated that Japan's population will peak in 2008 and decline thereafter. The urban structure is expected to change significantly due to this population decline. Kanagawa Prefecture in Japan, which is the target of this study, occupies a part of the Tokyo metropolitan area, and estimates have been published that show a decline in population from 2020. In response to such a future population decline, plans are being made for a compact city with the aim of optimizing the population distribution. On the other hand, Japan is a country with high potential for many natural disaster risks. In particular, the Tokyo metropolitan area has a high probability of earthquake occurrence and is an area with high earthquake risk.

We analyse the change of earthquake risk due to the future population decline and the change of earthquake risk by inducing a compact city utilizing population decline. In Kanagawa Prefecture in the metropolitan area of Japan, we analysed the forecast of the decrease in residential buildings due to population decline by structure, building age and building height. The seismic damage evaluation was carried out using the same three earthquake scenarios as the seismic damage assumed by Kanagawa Prefecture. The number of damaged buildings in the future was calculated for each earthquake scenario. The earthquake scenarios are 1) Tshin nanbu earthquake, 2) Miura Peninsula fault group earthquake and 3) Kanto earthquake. Building damage is estimated every 10 years from 2020 to 2040 due to population decline in each scenario. Next, we analyse the change in earthquake risk caused by the compact city policy due to population decline and other disaster prevention measures.

In this study, we examined the change of the earthquake risk by the compact city plan according to the future population decrease in Kanagawa prefecture.

Keywords: Earthquake risk, future population, number of damaged buildings, compact city, Location optimization plan.
\end{abstract}

\section{INTRODUCTION}

It has been reported that the population of Japan will decrease from a peak of 128.88 million in 2008 to a total of 49.59 million in 2100 . This change is a very sharp decrease. This change is a very rapid decrease [1]. Population decline is expected to change the composition of the city.

Since population decline is expected to progress throughout Japan in the future, it is necessary to formulate a location optimization plan suitable for the future population, aiming at a compact city for proper land formation. Residential location guidance aimed at the compact city is a new mechanism by which the Japanese government controls cities by 'guiding' them in their activities, including housing. As a response to Japan's declining population, this policy aims to maintain population density and rebuild sustainable cities with consideration for their productivity and the environment [2]. Figure 1 shows a conceptual diagram of location optimization measures.

Kanagawa Prefecture, which is the subject of research, is part of the Tokyo metropolitan area and has the population of 8.9 million, making it the second prefecture after Tokyo.

Kanagawa Prefecture forms a metropolitan area that includes 3.69 million people in Yokohama City and 1.53 million people in Kawasaki City in the area adjacent to Tokyo. Japan's declining population is no exception in Kanagawa Prefecture. 


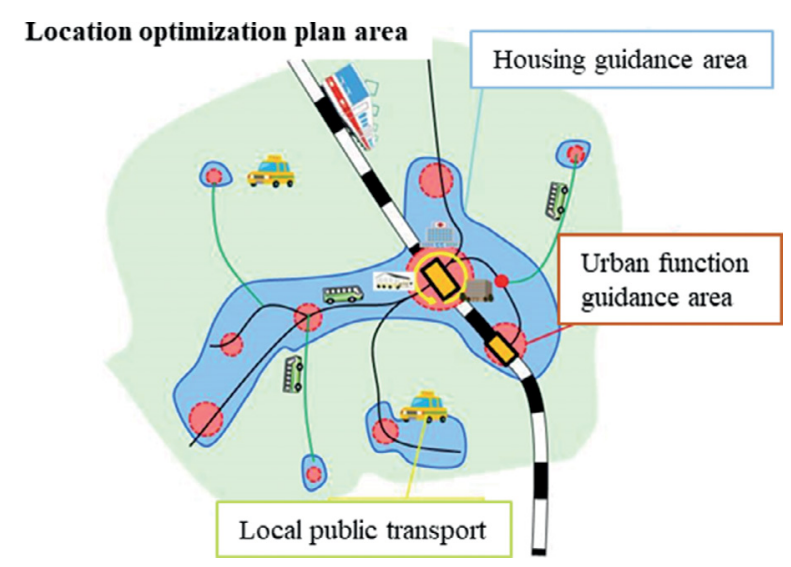

Figure 1: Conceptual diagram of location optimization measures.

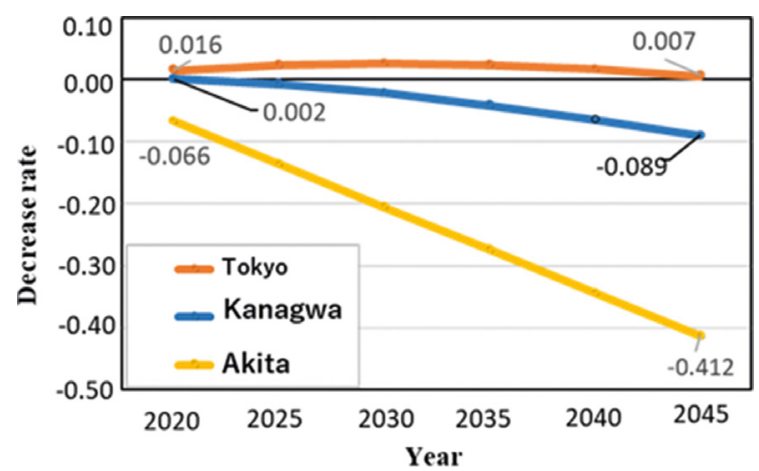

Figure 2: Future population change rate (Tokyo, Kanagawa, Akita).

The population of Kanagawa Prefecture peaked at about 9,174,000 in 2020 and was about $7,733,000$ in 2045, an estimated $8.9 \%$ decrease, or about 1,414,000 [3].

Figure 2 shows the population change rates of Tokyo, Kanagawa and Akita prefectures from 2020 to 2045 based on 2015.

In Japan, there are earthquakes beneath the Tokyo metropolitan area where there is a $70 \%$ probability of Magnitude 7 class earthquake occurring within 30 years in the southern Kanto region.

There is also a trench-type earthquake along the Sagami Trough, where 0\% to 5\% of Magnitude 8 class earthquakes occur within 30 years.

These are earthquakes that could damage the central functions of Japan.

Under such circumstances, it is expected that Japan's disaster risk will change significantly due to Japan's declining population [4][5].

In this study, we analyse the change of earthquake risk due to the future population decline and the change of earthquake risk by inducing a compact city utilizing population decline.

In Kanagawa Prefecture, we analysed the forecast of the decrease in residential buildings due to population decline by structure, building age and building height. The seismic damage 


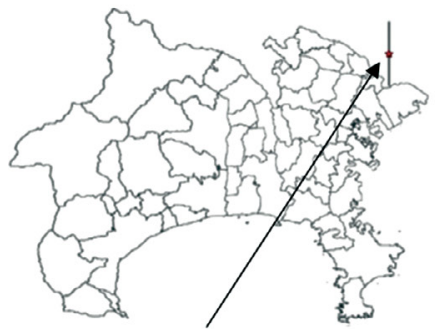

Toshin nanbu Earthquake

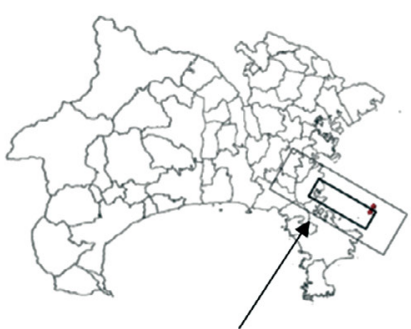

Miura Peninsula Faults Earthquake

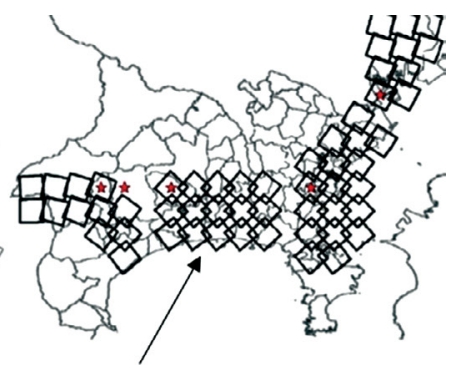

Taisho Kanto Earthquake

Figure 3: Scenario earthquake

Table 1: Overview of scenario earthquake.

\begin{tabular}{|c|c|c|}
\hline Scenario earthquake & Magnitude & Probability of occurrence \\
\hline $\begin{array}{l}\text { Earthquake centred directly under the } \\
\text { capital (Toshin nanbu earthquake) }\end{array}$ & 7.3 & $\begin{array}{l}\text { M7 class earthquakes in the South } \\
\text { Kanto region will be } 70 \% \text { in } 30 \text { years. }\end{array}$ \\
\hline Miura Peninsula Faults earthquake & 7.0 & $6 \%$ to $11 \%$ within 30 years \\
\hline Taisho Kanto earthquake & 8.2 & $\begin{array}{l}0 \% \text { to } 5 \% \text { within } 30 \text { years (occur- } \\
\text { rence interval from } 200 \text { to } 400 \text { years) }\end{array}$ \\
\hline
\end{tabular}

evaluation was carried out using the same three earthquake scenarios as the seismic damage assumed by Kanagawa Prefecture [6].

The number of damaged buildings in the future was calculated for each earthquake scenario.

The earthquake scenarios are 1) Tshin nanbu earthquake, 2) Miura Peninsula fault group earthquake and 3) Kanto earthquake.

Figure 3 shows a scenario earthquake. Scenario earthquakes are assumed based on past earthquake occurrences and active fault locations. Table 1 shows an overview of the three earthquake scenarios, and Fig. 4 shows their seismic intensity distributions.

Building damage is estimated every 10 years from 2020 to 2040 due to population decline in each scenario.

The Government of Japan is taking measures to implement a compact city in order to sustain the city against population decline [7]. The effects of location optimization measures have been implemented by yosida, onoue, miyazaki, etc., but none have targeted disasters [8] [9] [10].

Next, we analyse the change in earthquake risk caused by the compact city policy due to population decline and other disaster prevention measures.

\section{RISK ASSESSMENT OF FUTURE BUILDINGS}

\subsection{Buildings in the future}

To calculate future building damage, the number of buildings in each region in the future is calculated. Official Japanese surveys have statistics on the number of households by population and building type. The future population forecast was made by the cohort method using 


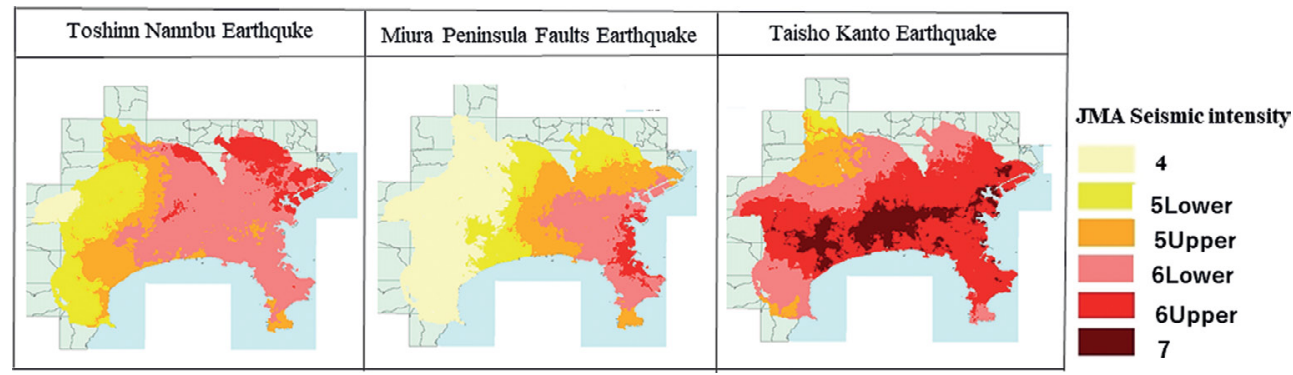

Figure 4: Distribution of seismic intensity class by scenario (Kanagawa Prefecture, Japan).

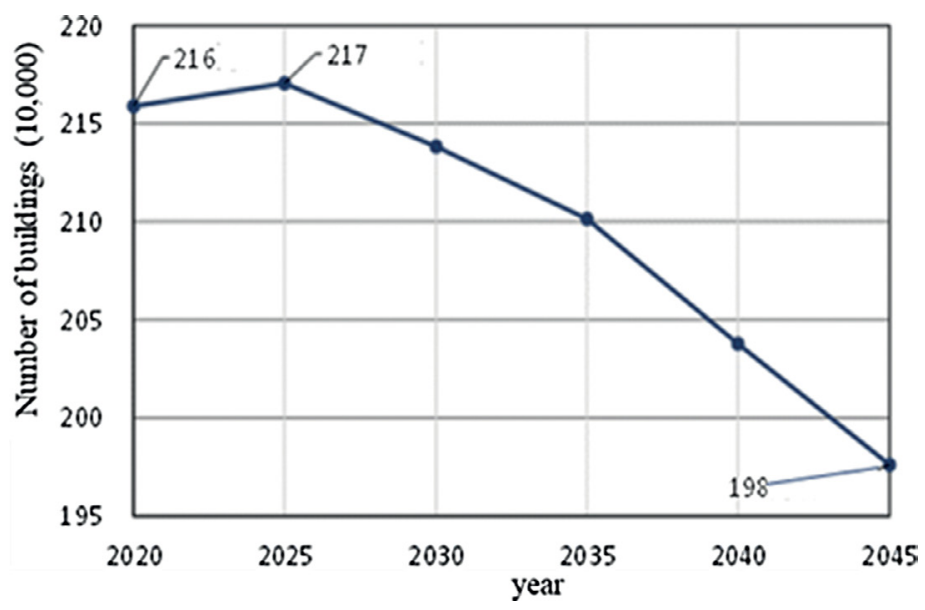

Figure 5: Changes in the number of future buildings in Kanagawa: 2020 2045.

the regional population and household data of 2015. The number of households was calculated using the future population.

The number of buildings by type of building in the future based on the number of households was estimated using the ratio of the number of current households and the number of buildings by type of building.

Figure 5 shows the change in the number of future buildings calculated every 5 years from 2020 to 2045.

Figure 6 shows the regional distribution of the number of buildings in 2020, 2030 and 2040.

As shown in Fig. 5, the number of buildings will peak at about 2.17 million in 2025 and then decrease to about 1.98 million in 2045.

This is an estimation result that the number of buildings will decrease by about $8.5 \%$ based on 2020.

Figure 6 shows the rate of change in the number of buildings every 10 years from 2020 to 2050. The change from 2020 to 2030 shows an increase in the number of buildings by $0.1 \%$ to $12.4 \%$ from the central part to the northeast. The change in the number of buildings from 2030 to 2040 often shows $0 \%$ or less or decreases even in the areas that had increased in the previous decade. 

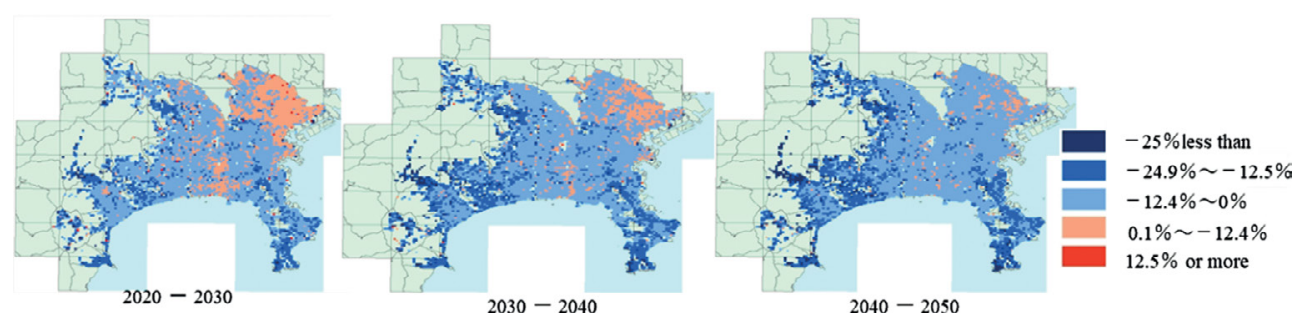

Figure 6: Rate of change in the number of buildings every 10 years: 2020-2040 (Kanagawa Prefecture, Japan).

\subsection{Earthquake damage prediction}

For earthquake damage prediction, it is necessary to give characteristics of the structure, building age, and building height of the building in addition to the regional distribution of the building. Figure 7 shows the damage of traditional Japanese wooden buildings and high-rise apartment buildings with seismic intensity 7. [11]

This setting is set for each municipality based on the quantity of residential land statistics.

In the building age, it is assumed that the building will be rebuilt or demolished with the passage of time, and the latest age classification will increase.

Therefore, assuming that the change in the proportion of each building age in 2008 and 2013 will change linearly after 2013 , we set the building age proportion for the next 30 years.

Future damage prediction is performed for the future building status set in this way. In this study, damage prediction was seismic damage.

For the calculation of earthquake motion damage, the damage function similar to the Kanagawa earthquake damage assumption was used.

As for damage estimation, the number of damaged buildings in future buildings was calculated for each earthquake scenario. The earthquake scenarios are (1) Toshin nanbu earthquake (directly under the capital), (2) Miura Peninsula fault group earthquake and (3) Taisho type Kanto earthquake.

Figure 8 shows the changes in the number of damaged buildings every 10 years from 2020 to 2040 in each scenario.

The largest number of damaged buildings by scenario earthquake was the Taisho-type Kanto earthquake, with a maximum of 1.16 million damaged in 2020. The damage is decreasing with age.

In each earthquake scenario, the number of building damage is highest in 2020. This is because the number of buildings is 2020, 2030 and 2040, which is the largest in 2020.

Figures 9 to 11 show the distribution of the number of damaged buildings from 2020 to 2040 in each scenario.

In these figures, many buildings are damaged mainly in areas with a seismic intensity of 6 upper due to the relationship with the seismic intensity distribution map in Fig. 4.

Figure 9 shows the damage caused by Toshin nanbu earthquake (directly under the capital).

From Fig. 9, there are damaged buildings in the eastern and central parts of Kanagawa prefecture from 2020 to 2030, but in 2040, the number of damaged buildings occurs only in the eastern part of Kanagawa prefecture adjacent to Tokyo. This is because the number of buildings increases in the eastern and central parts of Kanagawa prefecture from 2020 to 2030, but decreases from 2030 to 2040 . 


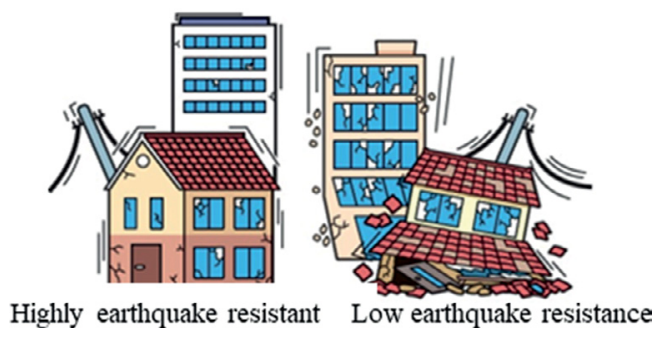

Figure 7: The damage of traditional Japanese wooden buildings and high-rise apartment buildings with seismic intensity of 7 .

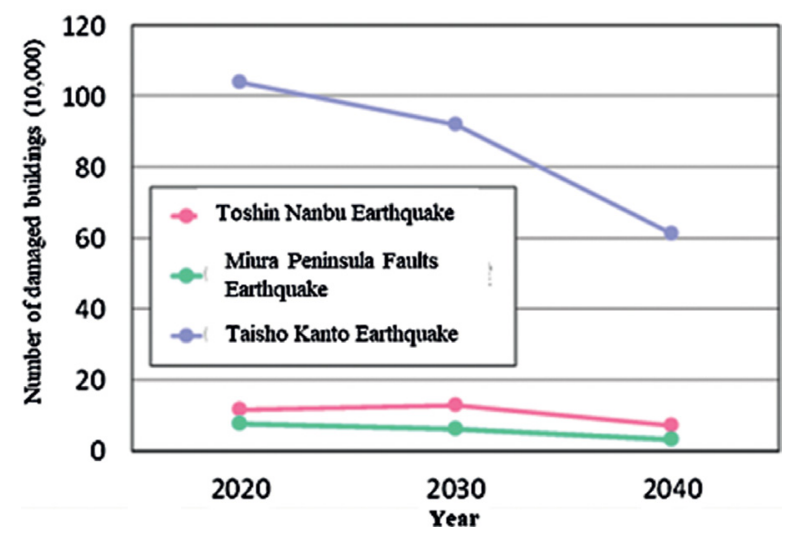

Figure 8: Number of damaged buildings in future buildings in Kanagawa: 2020-2040.

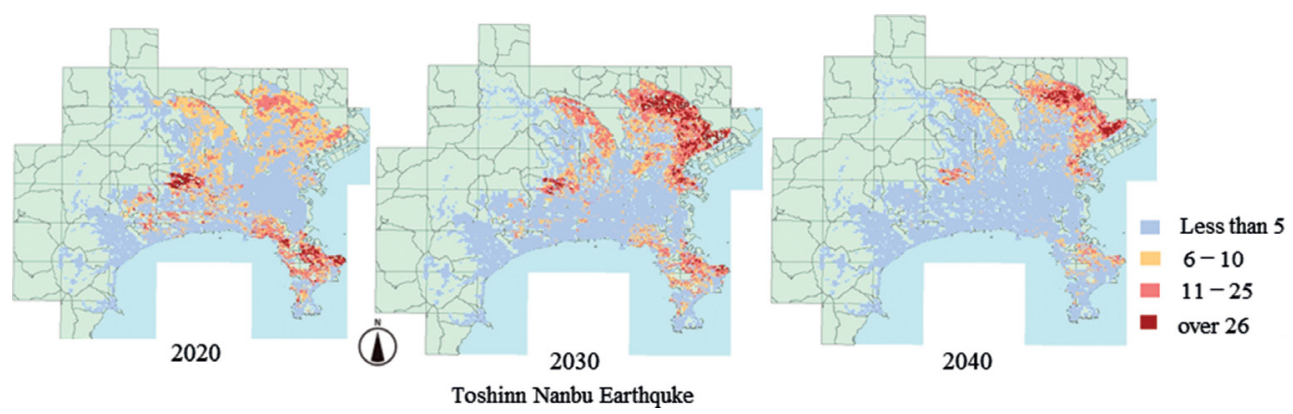

Figure 9: Change in distribution of damaged buildings: Toshin nanbu earthquake (Kanagawa Prefecture, Japan).

Figure 10 shows the damage of the Miura Peninsula Fault earthquake.

From this Fig. 10, damage is occurring in the entire Miura Peninsula in 2020, but damage is occurring only in the urban area on the east side of the Miura Peninsula in 2040, and the number of damaged buildings is decreasing in other areas.

Figure 11 shows the damage caused by the Taisho Kanto earthquake. 

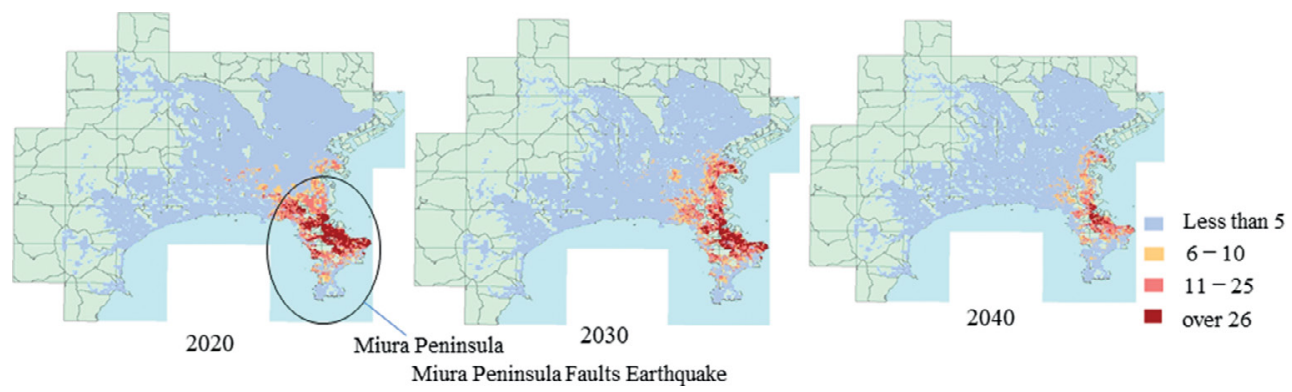

Figure 10: Change in distribution of damaged buildings: Miura Peninsula Faults earthquake (Kanagawa Prefecture, Japan).
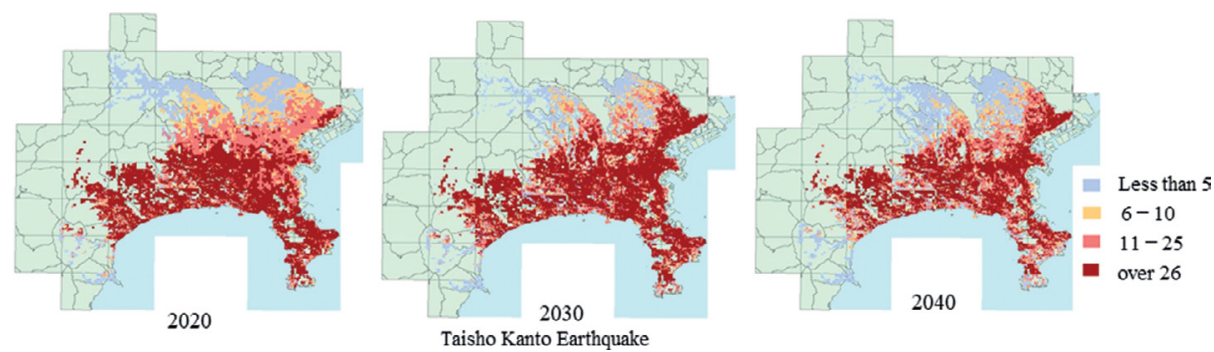

Figure 11: Change in distribution of damaged buildings: Taisho Kanto earthquake (Kanagawa Prefecture, Japan).

This earthquake will cause damage to buildings throughout Kanagawa prefecture. However, as the years pass, the areas where the number of damaged buildings has been decreasing will decrease.

\section{A STUDY ON SEISMIC RISK CHANGE DUE TO FUTURE COMPACT CITY}

In Japan, the number of buildings will decrease as the population declines, and the number of buildings damaged by future earthquakes will tend to decrease.

The results of the previous chapter are based on the assumption that the current state of population distribution will continue and that population will decrease on the assumption.

However, considering the sustainable development of cities as the population declines, it becomes necessary to make the cities compact.

The Government of Japan has formulated a location optimization plan in response to the decrease in the number of buildings due to the future population decline. This location optimization plan may lead to the reduction of earthquake risk, which is a serious risk in Japan, by making cities more compact.

Here, we will examine the effects of seismic risk on location optimization by inducing housing location aiming for a compact city due to population decline.

\subsection{Effect of location optimization plan by location induction}

Consider the change in earthquake risk caused by the induction of housing location due to population decline. 
As a housing guidance measure, the number of damaged buildings in the case of applying the models of the following two extreme patterns was calculated for each scenario and compared.

(1) Levelling method

Number of buildings damaged by scenario when the number of households in the future is relocated so that the number of households is equal to the existing 250-m mesh in Kanagawa prefecture

(2) Integration method

Number of buildings damaged by scenario when the number of households in the future is $250-\mathrm{m}$ mesh in Kanagawa prefecture and residents in areas where the number of households is 100 or less are moved to areas where the number of households is 300 or more.

\subsection{Comparison of analysis results of location guidance methods}

Figure 12 shows the number of damaged buildings in the future for each scenario earthquake in 2040, and the distribution of the number of damaged buildings when the levelling method and the Integration method are used.

Table 2 shows a comparison table of the number of damaged buildings in Fig. 12.

In Fig. 12, the effect of the levelling method reduces the number of damaged buildings in a three-scenario earthquake compared with the case where no house guidance is implemented.

In particular, the Taisho Kanto earthquake, which has a distribution of the number of damaged buildings throughout Kanagawa prefecture, had the largest reduction effect, a decrease of $41.6 \%$.

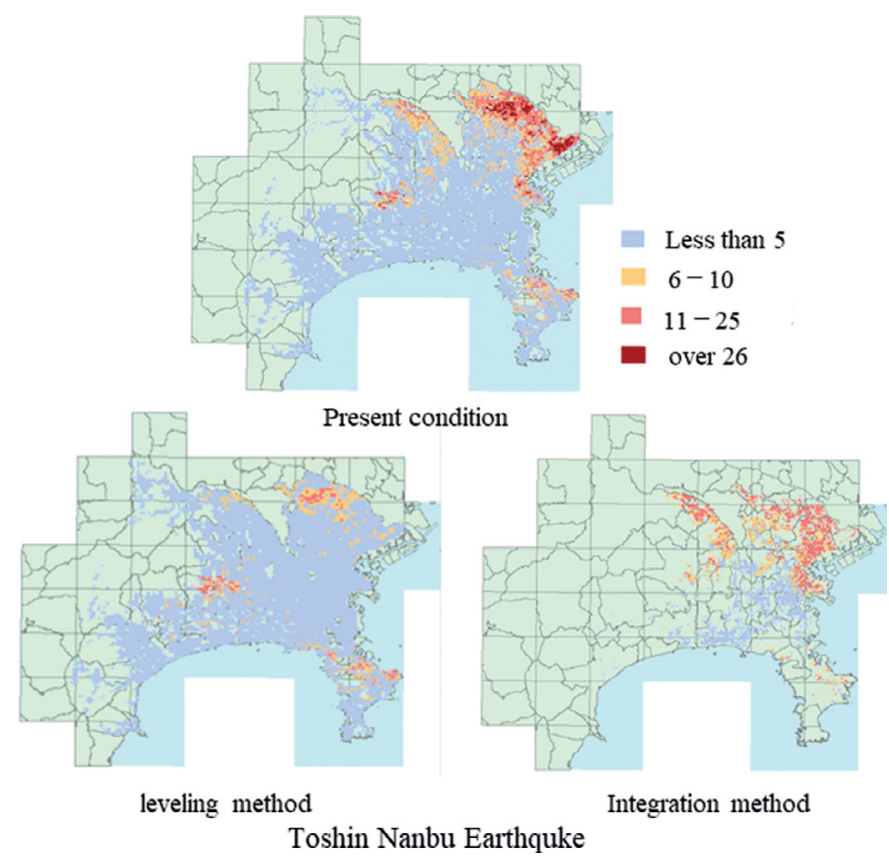

(a) 


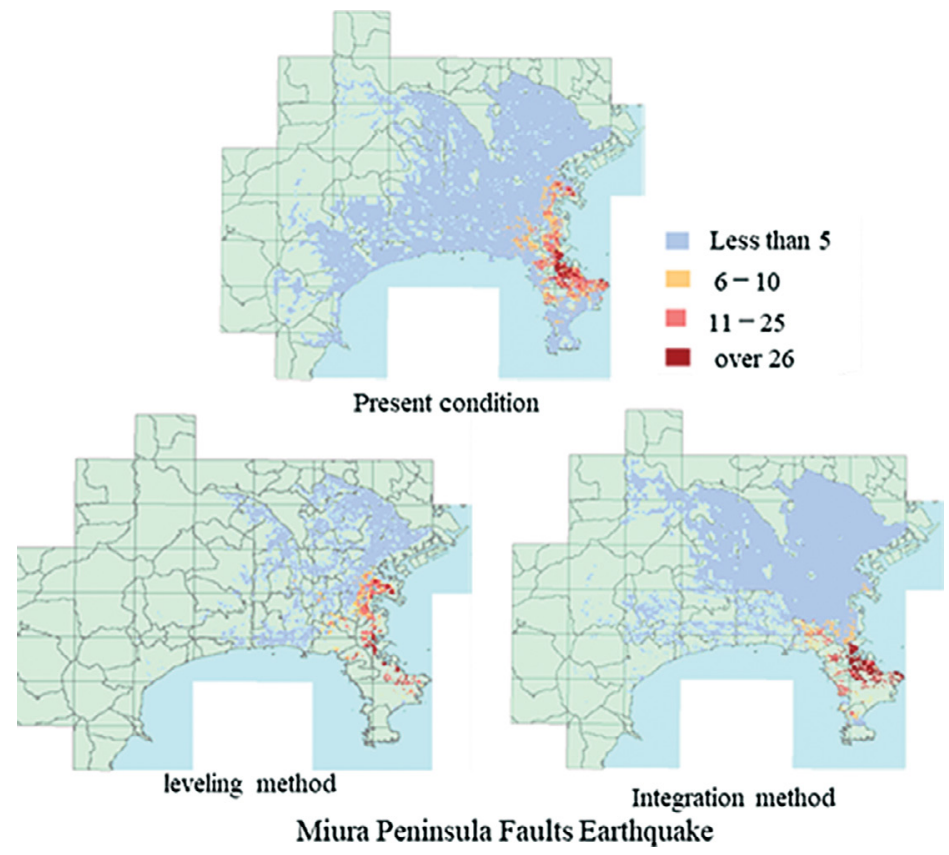

(b)

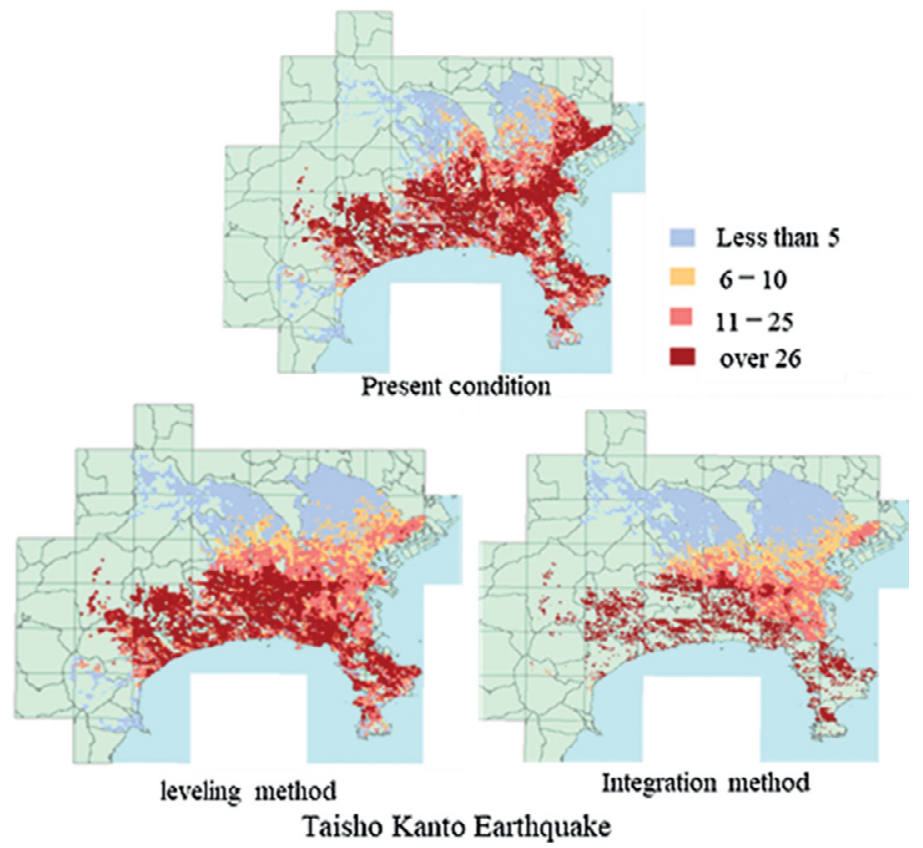

(c)

Figure 12: Distribution of building damage due to location guidance measures. (a) Toshin nanbu earthquake; (b) Miura Peninsula fault earthquake; (c) Taisho Kanto earthquake (Kanagawa Prefecture, Japan). 
Table 2: Number of building damage due to location guidance measures

\begin{tabular}{llll}
\hline & $\begin{array}{l}\text { Toshin nanbu } \\
\text { earthquake }\end{array}$ & $\begin{array}{l}\text { Miura Peninsula } \\
\text { Faults earthquake }\end{array}$ & $\begin{array}{l}\text { Taisho Kanto } \\
\text { earthquake }\end{array}$ \\
\hline Present condition & 70,408 & 30,418 & 611,155 \\
Levelling method & $60,723(-13.8 \%)$ & $19,103(-37.2 \%)$ & $356,788(-41.6 \%)$ \\
Integration method & $69,993(-0.6 \%)$ & $15,464(-49.2 \%)$ & $291,016(-52.4 \%)$ \\
\hline
\end{tabular}

As a result of the Integration method, it was possible to confirm the reduction in the number of damaged buildings in the three scenario earthquakes. However, the result of the Toshin nanbu earthquake was a decrease of $0.6 \%$, which revealed that there was almost no reduction effect compared with other earthquake scenarios. Although this will lead to future housing guidance to existing population-concentrated areas, it became clear that the Toshin nanbu earthquake has a high seismic intensity in the existing population-concentrated areas, increasing the earthquake risk.

This shows that the performance as a city will increase due to the compact city, but the risk may increase from the viewpoint of earthquake risk. However, the Integration method confirmed that the reduction values for Taisho Kanto earthquake and Miura Peninsula fault earthquake were $49.2 \%$ and $52.4 \%$, respectively, which showed high reduction effect.

From the analysis of this centralization method, it became clear that housing-induced compact city can reduce the earthquake risk of the city.

By considering the relationship between the city (scale, location) to be compacted and the earthquake scenario (location, magnitude, probability of occurrence), both efficient and sustainable compact city and seismic risk reduction of the city can be achieved.

\section{CONCLUSION}

In this study, we examined the change in earthquake risk due to the future population decrease and the change in earthquake risk due to the compact city caused by housing induction due to population decrease. The analysis target was conducted in Kanagawa prefecture, which is in the metropolitan area of Japan, and the earthquake risk was clarified by calculating the number of future buildings damaged in three earthquake scenarios in Kanagawa prefecture.

Then, we examined whether the location optimization plan could reduce the size of the city and lead to the reduction of earthquake risk, which is a serious risk in Japan.

The results obtained are as follows.

1. The future population of Kanagawa prefecture in 2050 will decrease, and it will decrease by about $11.7 \%$ compared with 2020 . That is, the population will decline in some areas from 2020 to 2040, and from 2040 to 2050, the population will decline throughout the prefecture. As a result, the number of future buildings in Kanagawa Prefecture will both peak at 2025 and decrease.

2. The future damage to buildings due to the earthquake was calculated for each of the three earthquake scenarios, and it became clear that the Taisho Kanto earthquake, which has the widest range of seismic intensity 6 upper and 7, has the largest number of damaged buildings. However, in all three scenario earthquakes, the number of damaged buildings will decrease from 2020 to 2040. 
3. As a measure for population decline, local governments are promoting compact cities by inducing housing locations. The compact city showed the possibility of achieving both efficient sustainability and seismic risk reduction, depending on the relationship between urban characteristics (scale/location) and earthquake scenarios (location, magnitude, probability of occurrence).

\section{REFERENCES}

[1] Economic and Social Research Institute, Cabinet Office The ESRI International Collaboration Project 2016/17 "Empirical Analysis on Population Decline and Aging in Japanese Economy (The Effects on Macroeconomic Economic Growth)” No.196, 2017

[2] Ministry of Land, Infrastructure, Transport and Tourism: Guide for location optimization planning, 2019.4.

[3] Kanagawa Prefecture: Future Population Estimate / Future Household Estimate (Japanese), 2019. https://www.pref.kanagawa.jp/docs/r5k/cnt/f4895/p15276.html

[4] Tomofumi Ikenaga, Ohara Miho: Analysis of Population Distribution Exposed to Natural Hazards in Japan-- Toward Better Land Use Considering Future Depopulation (Japanese), Transactions of Social safety science No.25, 2015.3

[5] Haili Chen, Norio Maki, Haruo Hayashi: Examining The Regional Exposure Characteristics Under Yokai Tonankai and Nankai Earthquake Under The Consideration of Future population Decline(Japanese), Journal of Natural Disaster Science 29-3 365-380 (2010)

[6] Kanagawa Prefecture: Kanagawa Prefecture Earthquake Damage Assumption Report (Japanese), 2018.

[7] Ministry of Land, : Infrastructure and Transport Overview of location optimization plan (Japanese), 2014.

[8] Katumi Yoshida, : The Journal of the Land Institute, Population declining society and urban law--Regional optimization plan system and actual conditions--(Japanese), No.147, 2018

[9] Onoue Yusuke: Compact town development based on location optimization planning system, Ministry of Land, Infrastructure(Japanese), Transport and Tourism City Bureau, 2018

[10] Shinya Miyazaki, Shinji Ikaruga, Takeshi Kobayashi, Junhwan Song: Study on The Method of Induction Area and Induction Policy of City Which Established Location Optimization Plan, Journal of Technology and Design, Architectural Institute of Japan Vol. 25, No.60, 881-886, Jun., 2019

[11] Japan Meteorological Agency: Seismic intensity and shaking conditions, 2009.3. 